\title{
ANALYSIS AND IMPLEMENTATION OF FPGA CONTROL OF ASYMMETRIC MULTILEVEL INVERTER FOR FUEL CELL APPLICATIONS
}

\author{
S Dharani* \& Dr.R.Seyezhai** \\ Department of EEE, SSN College of Engineering, Chennai, India.
}

\begin{abstract}
This paper presents an Asymmetric Multilevel Inverter (AMLI) with reduced number of switches for fuel cells and suitable for high voltage and high power applications. Among the several types of multilevel inverter, AMLI is a suitable choice to generate the higher number of output voltage levels with fewer switches and sources. A novel hybrid modulation strategy based on Variable Amplitude Phase Opposition and Disposition (VAPOD) is implemented using FPGA for AMLI which is powered by Proton Exchange Membrane Fuel Cell (PEMFC). The operation of the proposed AMLI is verified with simulation and experimental results.
\end{abstract}

\section{Keywords}

AMLI, POD, FPWM, PEMFC.

\section{INTRODUCTION}

Multilevel inverter offers various applications ranging from medium to high voltage such as in renewable energy sources, industrial drives, electric vehicles etc., A conventional single -phase inverter produces a voltage levels of $+\mathrm{V}_{\mathrm{DC}}, 0$ and $-\mathrm{V}_{\mathrm{DC}}$ which means it is able to produce quasisquare output voltage waveform. This output is not advisable to use for any AC system as an input. To get nearly sinusoidal waveform, a multilevel inverter is employed. By using MLI, ripple content and voltage stress across the switches get reduced. So, MLI is preferred over the conventional inverter. There are two major topologies of cascaded MLI namely Symmetric MLI and Asymmetric MLI. In SMLI, the DC voltage sources value are equal whereas in AMLI, unequal DC voltage sources are used. AMLI is preferred over the SMLI because it produces a higher voltage levels with same number of switches when compared with SMLI.

This paper proposes a novel AMLI to produce fifteen level output voltage waveform by using only seven switches. The proposed AMLI is powered by Proton Exchange Fuel Cell which is the best choice compared to other types. Several modulation techniques have been reported in the literature [1]. In this paper, a hybrid Variable Amplitude POD is implemented in AMLI to get reduced harmonic content in the output voltage waveform when compared with other POD based modulation technique. 


\section{BASIC OPERATION OF AMLI}

AMLI is recommended to provide increased number of levels with reduced switches when compared with symmetric MLI. Therefore, this topology tends to increase reliability and efficiency than other topologies [2,3]. Figure 1 shows the circuit configuration of AMLI for producing fifteen level output voltage waveform.

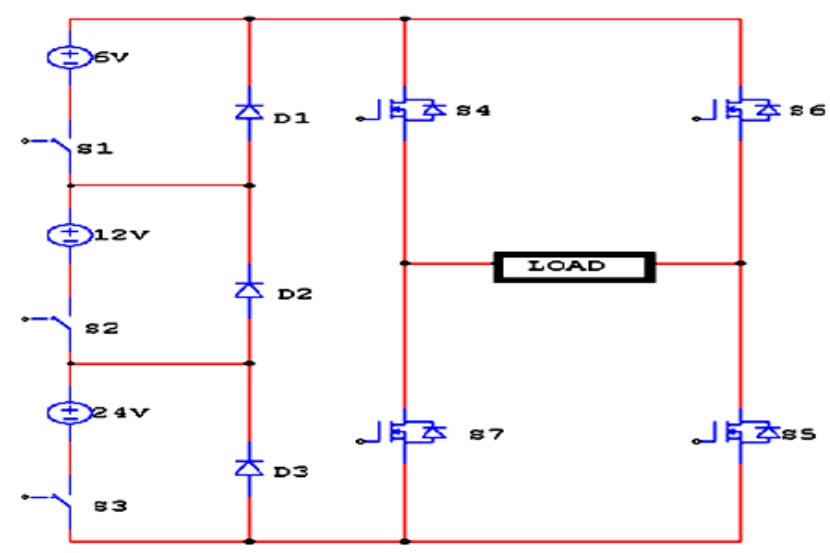

Figure1: Asymmetric Multilevel Inverter

TABLE 1: CONDUCTION STATE OF AMLI

\begin{tabular}{|c|c|c|c|c|c|c|c|}
\hline $\mathbf{S}_{\mathbf{1}}$ & $\mathbf{S}_{\mathbf{2}}$ & $\mathbf{S}_{\mathbf{3}}$ & $\mathbf{S}_{\mathbf{4}}$ & $\mathbf{S}_{\mathbf{5}}$ & $\mathbf{S}_{\mathbf{6}}$ & $\mathbf{S}_{\mathbf{7}}$ & $\mathbf{V}_{\mathbf{0}}$ \\
\hline On & Off & Off & On & On & Off & Off & 6 \\
\hline Off & On & Off & On & On & Off & Off & 12 \\
\hline On & On & Off & On & On & Off & Off & 18 \\
\hline Off & Off & On & On & On & Off & Off & 24 \\
\hline On & Off & On & On & On & Off & Off & 30 \\
\hline Off & On & On & On & On & Off & Off & 36 \\
\hline On & On & On & On & On & Off & Off & 42 \\
\hline Off & Off & Off & Off & On & On & Off & 0 \\
\hline On & Off & Off & Off & Off & On & On & -6 \\
\hline Off & On & Off & Off & Off & On & On & -12 \\
\hline On & On & Off & Off & Off & On & On & -18 \\
\hline Off & Off & On & Off & Off & On & On & -24 \\
\hline On & Off & On & Off & Off & On & On & -30 \\
\hline Off & On & On & Off & Off & On & On & -36 \\
\hline ON & ON & ON & OFF & OFF & ON & ON & -42 \\
\hline
\end{tabular}

Table 1 shows the conduction state for seven switches in AMLI. From the conduction table, two switches must be switched $\mathrm{ON}$ in inverter unit to generate positive and negative cycle of output voltage waveform and based on the conduction of the three switches in the asymmetric basic unit, the output voltage levels and values are determined.For this proposed AMLI, geometric progression with the power of two is used to determine the binary configuration of voltage sources. In AMLI, the asymmetric basic unit includes three sources and three switches and full bridge inverter unit includes four switches. Thus, fifteen level output voltage waveform is 
produced by using seven switches and three sources. For the proposed asymmetric structure, the DC voltage source is chosen based on the following algorithm.

$\mathrm{V}_{1}=\mathrm{V}$

$\mathrm{V}_{\mathrm{m}}=2^{(\mathrm{m}-1)} * \mathrm{~V}$ for $\mathrm{m}=2,3, \ldots \mathrm{n}$

The number of levels and the maximum output voltage is determined by the below equations

$\mathrm{N}_{\text {Level }}=2^{(\mathrm{n}+1)}-1$.

$\mathrm{V}_{0, \max }=\left(2^{\mathrm{n}-1}\right) * \mathrm{~V}$

$\mathrm{N}_{\text {MOSFET }}=\mathrm{n}+4$

where $\mathrm{n}$ represents number of switches in asymmetric basic unit.

\section{HYBRID MODULATION STRATEGIES FOR AMLI}

Normally, the performance of an inverter is mainly decided by its modulation technique $[4,5]$. For AMLI, different low and high frequency techniques have been employed. But this paper presents a hybrid modulation technique that comprises of fundamental frequency modulation and sinusoidal pulse width modulation (SPWM). The fundamental frequency modulation technique is used for switches in full bridge inverter unit to reduce switching losses. To get reduced harmonic contents, SPWM is used for three switches in asymmetric basic unit [6,7]. The various hybrid modulation techniques based on POD, APOD, PD and PS are analyzed based on THD values. From the analyses result as discussed in [1], the POD modulation technique is the suitable one for the proposed AMLI. To improve the spectral quality of the output, the modified technique based on the POD modulation is used. The Variable Amplitude POD is implemented for AMLI with reduced THD of 9.92\% than Variable Amplitude Carrier Overlapping POD, Variable Frequency POD and Inverted Sine POD.

\subsection{APOD HYBRID MODULATION TECHNIQUE}

In variable amplitude POD PWM, several carriers with single modulating signal are used. In this technique, the carrier signals located in above zero level and below zero level are in phase and out of phase by $180^{\circ}$ respectively. For the proposed AMLI to generate fifteen level output voltage waveform, four triangular carrier signals are used. By using triangular carrier signals, the ripple content in the output voltage gets reduced and the spectral quality is improved.

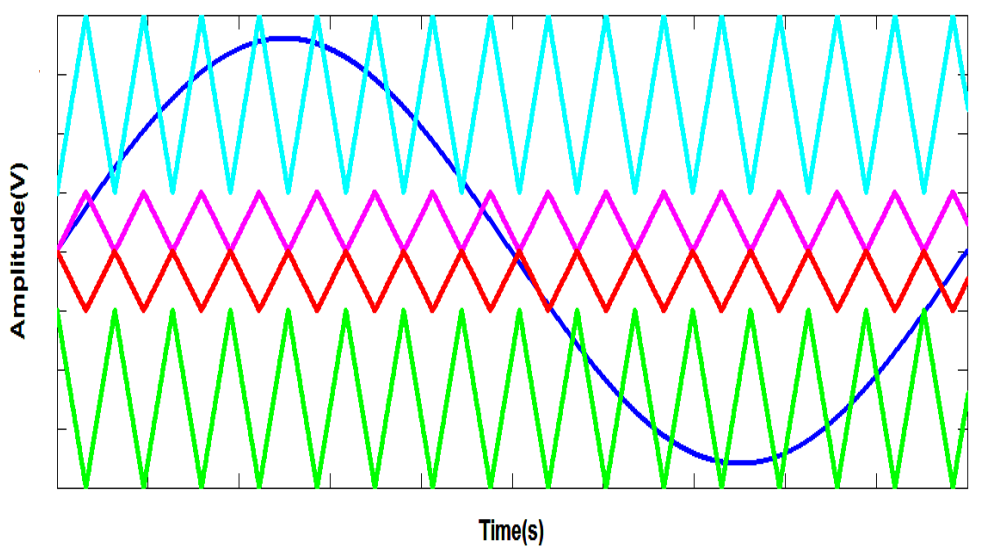

Figure 2: Carrier and Reference signals for VAPOD 
Figure 2 shows the hybrid modulation technique for 15- level MLI, four carriers with the same frequency $f_{c}$ and variable amplitude $A_{c}$. In this modulation technique, the two carriers in the middle portion have same amplitude and another two carriers above and below the axis have same amplitude but different from previous one. Because of the different magnitude carrier signals, the third harmonic distortion gets reduced. Here, the reference waveform is sinusoidal with peak to peak amplitude of $A_{m}$ and frequency $f_{m}$. Sinusoidal zero amplitude is centered in the middle of the four carrier set. By comparison based on the amplitude of the carrier and reference waveform, thee conduction state of the switches is determined. The amplitude modulation index $\mathrm{m}_{\mathrm{a}}$ and frequency modulation index $\mathrm{m}_{\mathrm{f}}$ for this technique are

$\mathrm{m}_{\mathrm{f}}=\mathrm{f}_{\mathrm{c}} / \mathrm{f}_{\mathrm{r}}$

$\mathrm{m}_{\mathrm{a}}=2 \mathrm{~A}_{\mathrm{r}} /\left(\mathrm{m}^{*} \mathrm{~A}_{\mathrm{c}}\right)$

For the proposed AMLI, these multicarrier arrangements for VAPOD based hybrid modulation have amplitude modulation of 0.9 and frequency modulation of 63.

\section{SIMULATION RESULTS}

Figure 3 shows the simulink model of asymmetric multilevel inverter for generating fifteen level output voltage waveform by using seven switches. Here, the AMLI is powered by PEM fuel cell. To produce $6 \mathrm{~V}, 12 \mathrm{~V}$ and $24 \mathrm{~V}$ voltages, 10,20 and 40 fuel cells are connected in series[8] respectively. In this figure 3, the subsystem shows the modeling of PEM fuel cell stack.

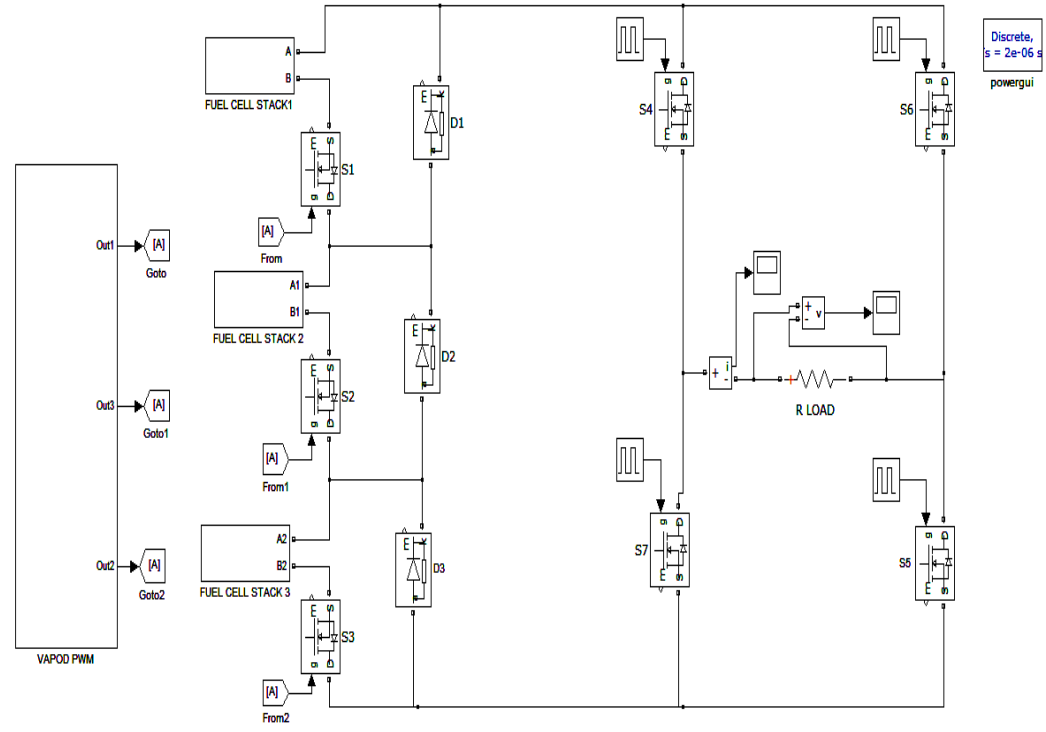

Figure 3: Simulink model for interface of PEMFC and AMLI

The simulation parameters for AMLI is shown in table:2. Figure 4(a) shows the pulse pattern by VAPOD hybrid modulation technique for asymmetric basic unit switches. Figure 4(b) shows the gating pattern for AMLI by fundamental frequency modulation technique for full bridge inverter unit. 
Table :2 Simulation parameters for AMLI

\begin{tabular}{|l|l|}
\hline PARAMETER & Values \\
\hline Fuel cell voltage $\left(\mathrm{V}_{1}\right)$ & $6 \mathrm{~V}$ \\
\hline Fuel cell voltage $\left(\mathrm{V}_{2}\right)$ & $12 \mathrm{~V}$ \\
\hline Fuel cell voltage $\left(\mathrm{V}_{3}\right)$ & $24 \mathrm{~V}$ \\
\hline Fundamental Frequency $\quad\left(\mathrm{f}_{\mathrm{s}}\right)$ & $50 \mathrm{~Hz}$ \\
\hline $\begin{array}{l}\text { Frequency modulation index, } \\
\left(\mathrm{m}_{\mathrm{f}}\right)\end{array}$ & 63 \\
\hline Amplitude modulation index, $\left(\mathrm{m}_{\mathrm{a}}\right)$ & 0.9 \\
\hline Switching Frequency $\left(\mathrm{f}_{\mathrm{c}}\right)$ & $3150 \mathrm{~Hz}$ \\
\hline Load Resistance & $10 \mathrm{ohm}$ \\
\hline
\end{tabular}
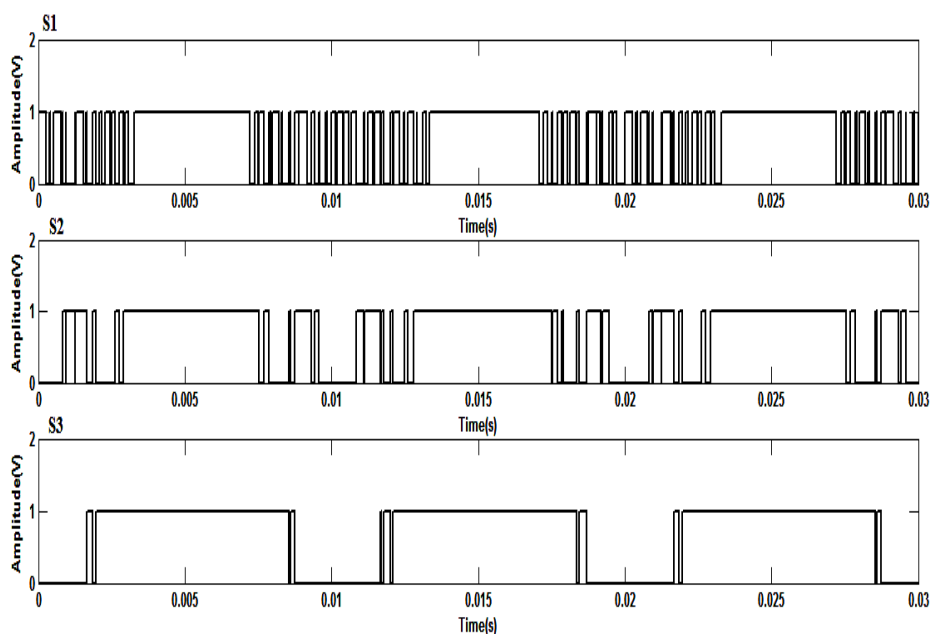

Figure 4(a): Gate pulses for Asymmetric basic unit switches
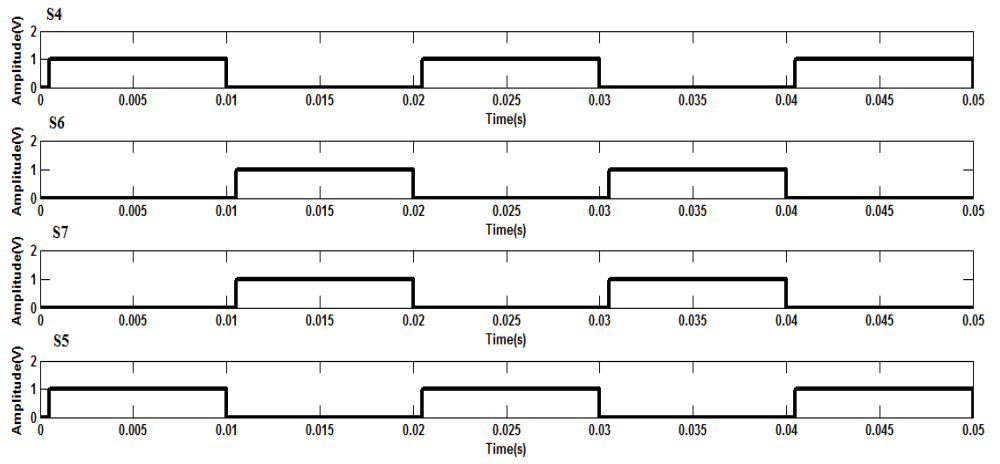

Figure 4(b): Gate pulses for Full bridge inverter unit switches 
The desired output voltage level is produced by using the proper switching sequence for all the switches in the proposed AMLI. Thus, the 15- level output voltage is produced from 3 sources and 7 switches with reduced THD of $9.92 \%$ by using VAPOD modulation technique. So, VAPOD modulation method is the best candidate for the proposed inverter powered by PEMFC. Figure 5 shows the output voltage waveform of AMLI and its THD analysis is shown in the figure 6.

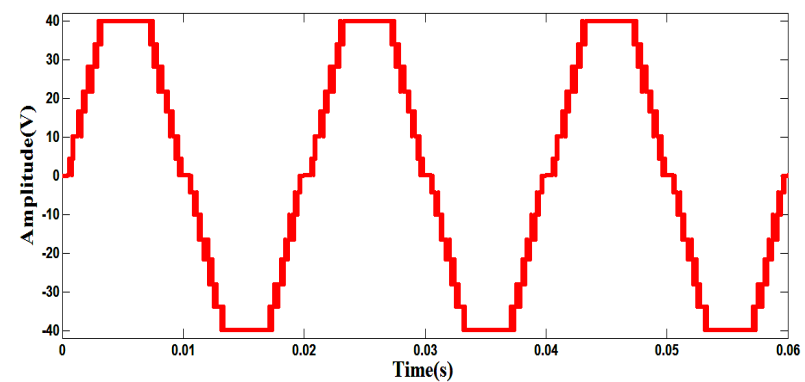

Figure 5: Simulation Results of 15- level AMLI

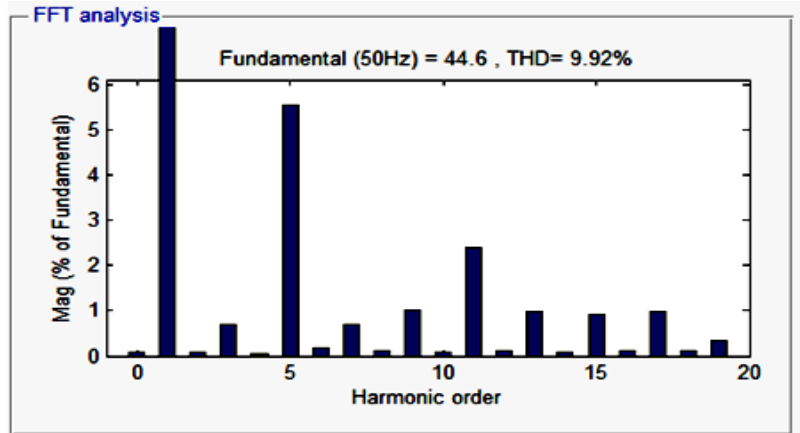

Figure 6: FFT analysis of VAPOD PWM

From the graph, the desired amplitude modulation index and frequency modulation index is selected based on the comparison of voltage THD values. The amplitude modulation index is 0.9 and the frequency modulation index is 63 with switching frequency of $3150 \mathrm{~Hz}$ are selected for AMLI to produce fifteen level output voltage waveform with reduced total harmonic distortion of $9.92 \%$.

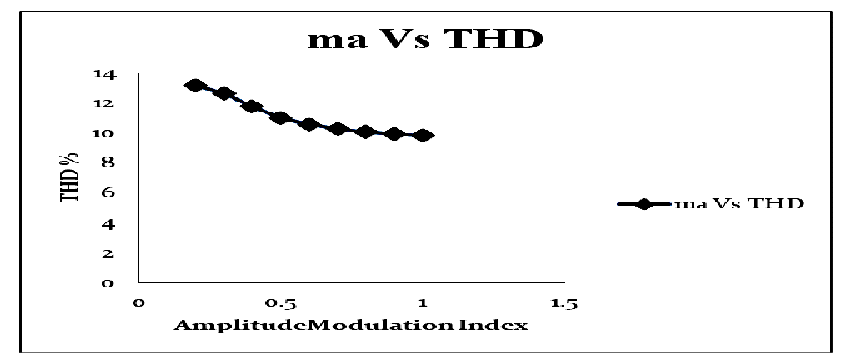

Figure 7: Amplitude Modulation Index Vs THD 


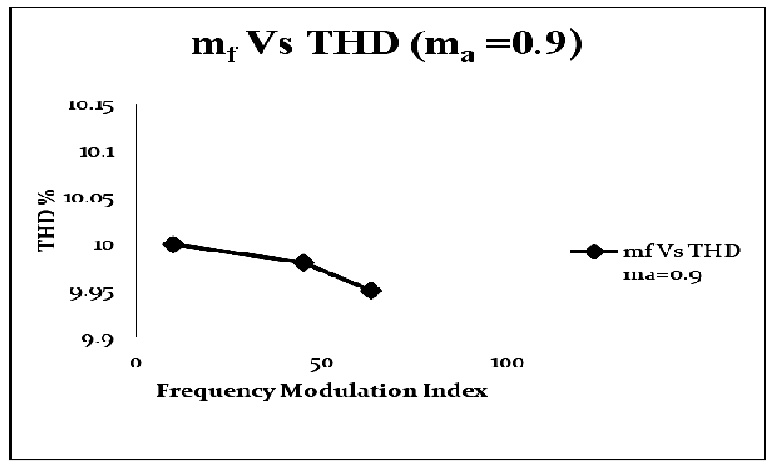

Figure 8: Frequency Modulation Index Vs THD

Table 3: Comparison of POD based PWM technique

\begin{tabular}{|c|c|}
\hline $\begin{array}{c}\text { POD based Hybrid } \\
\text { Modulation Technique }\end{array}$ & $\begin{array}{c}\text { Total Harmonic } \\
\text { Distortion }\end{array}$ \\
\hline VAPOD & $9.92 \%$ \\
\hline VACOPOD & $11.09 \%$ \\
\hline VFPOD & $11.14 \%$ \\
\hline ISPOD & $10.34 \%$ \\
\hline
\end{tabular}

By comparing the THD values of various POD based PWM technique as in table 3, Variable Amplitude POD produces better output with reduced 9.92\% THD.

Table 4: Performance Parameters for VAPOD

\begin{tabular}{|c|c|}
\hline Parameters & Calculated Values \\
\hline $\begin{array}{c}\text { THD(Total harmonic } \\
\text { Distortion) }\end{array}$ & $9.92 \%$ \\
\hline WTHD (Weighted THD) & $1.174 \%$ \\
\hline DF (Distortion Factor) & $0.238 \%$ \\
\hline HSF(Harmonic spread factor) & $4.05 \%$ \\
\hline
\end{tabular}

For VAPOD, the amplitude modulation index $\left(\mathrm{m}_{\mathrm{a}}\right) \quad 0.9$ is selected and the performance parameters[9] is calculated and shown in the table 4.

\section{EXPERIMENTAL RESULTS}

To validate the simulation results of the asymmetric multilevel inverter, the experimental results are presented in this section. For the proposed MLI as shown in the figure 9 has been used for the experimental studies. The resistance load, INR 480 diode and IRFP460 MOSFET are used in the experimental setup. The switching pattern for the seven switches is generated by using SPARTAN 3E FPGA with the software of ISE project navigator. The interface of FPGA kit and gate drive circuit is shown in the figure 10. The generated switching pulses is given to gate drive circuits which drives seven switches in the asymmetric multilevel inverter. 


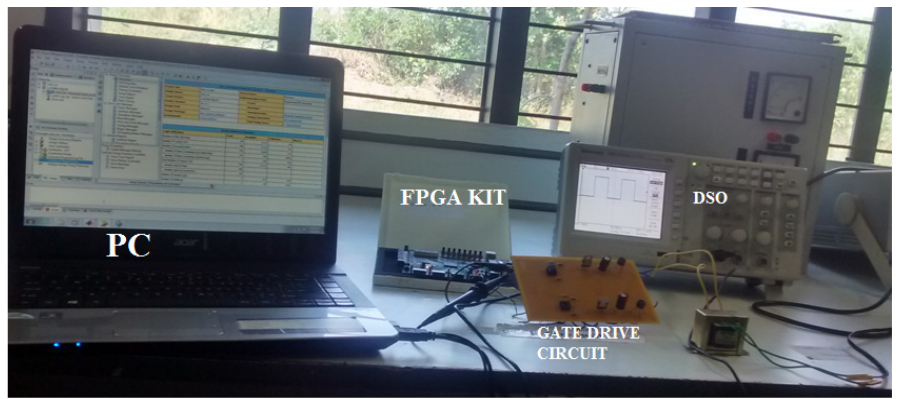

Figure 9: Interface of FPGA kit and Gate Drive circuit

Variable Amplitude POD modulation technique is used for three switches in asymmetric basic unit which is shown in the figure 10(a) and for four switches in inverter unit, fundamental frequency modulation technique is used. The gating pulse generated by FPGA kit and gate drive circuit is shown in the figure $10(\mathrm{~b})$

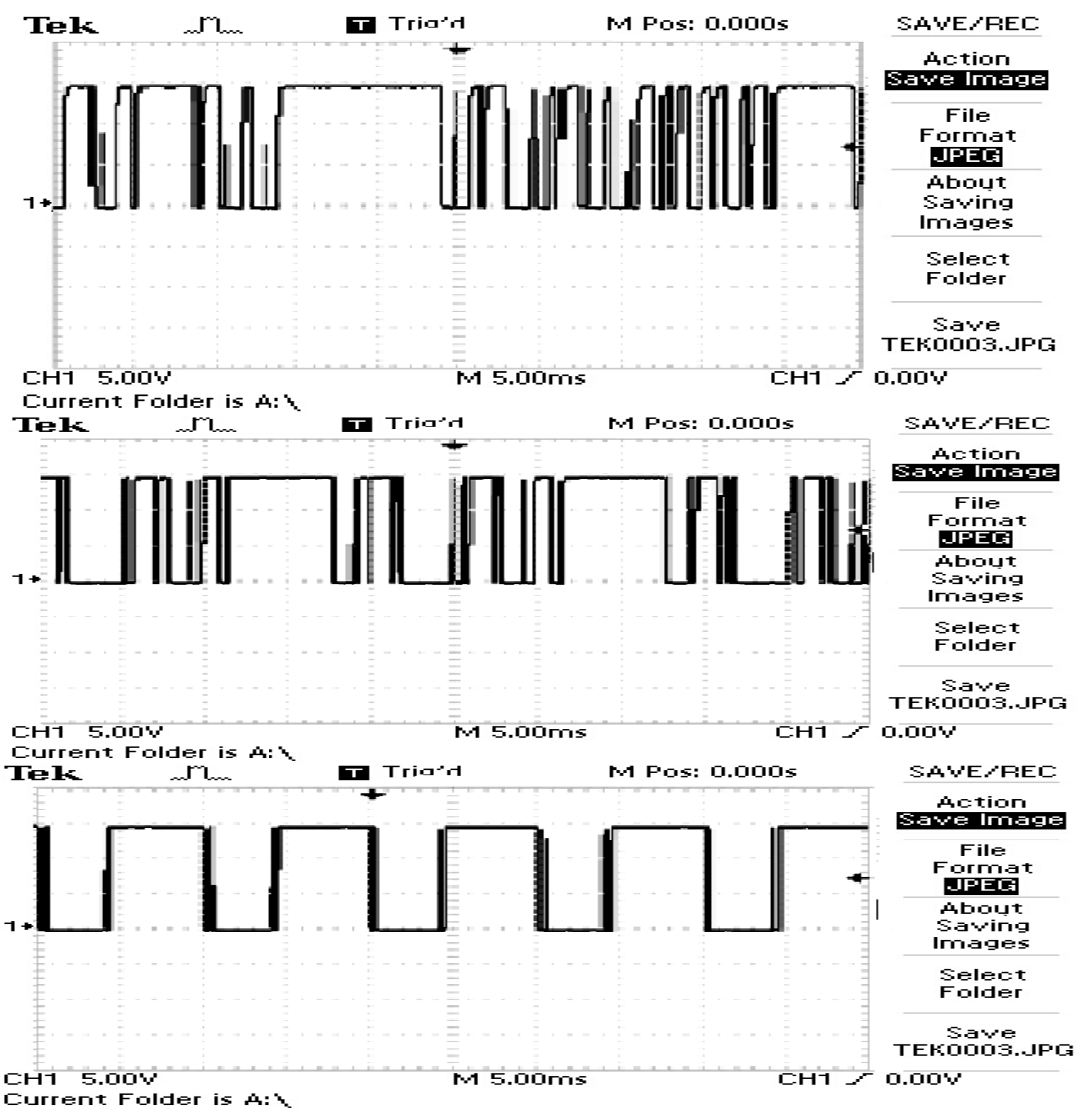

Figure 10(a): Gating pattern for $\mathrm{S}_{1}, \mathrm{~S}_{2}$ and $\mathrm{S}_{3}$ switches by VAPOD technique 
International Journal of Advances in Materials Science and Engineering (IJAMSE) Vol.4, No.4, October 2015

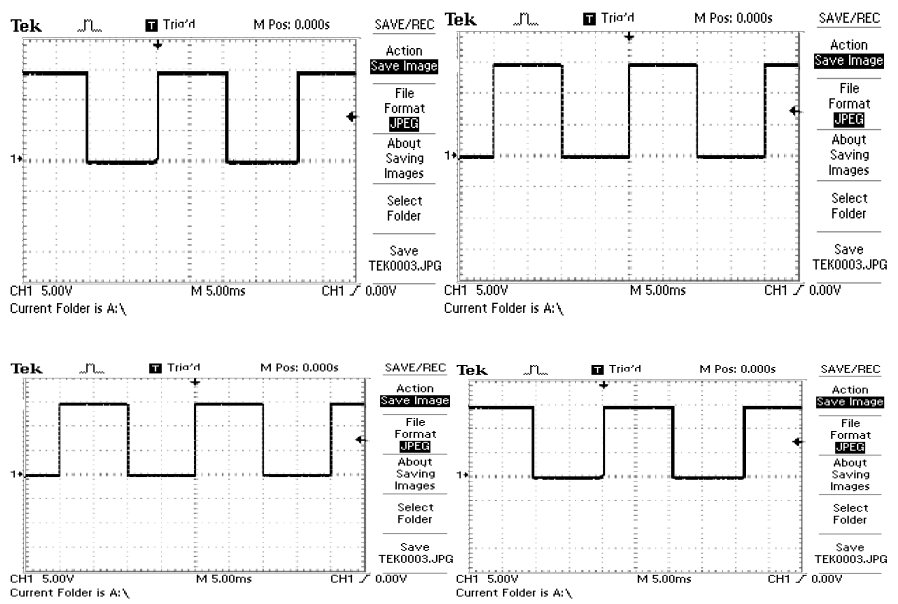

Figure 10(b) : Gating pulses for 4 switches in inverter unit by fundamental frequency modulation

Figure 11 shows the prototype of fifteen level asymmetric multilevel inverter with FPGA kit and gate drive circuit. Figure 12 shows the experimental results of the proposed AMLI.

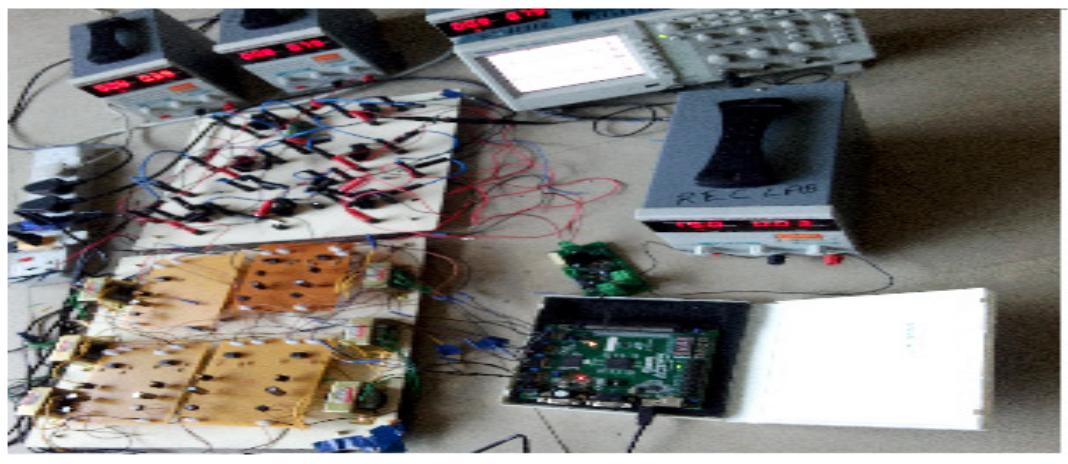

Figure 11: Experimental setup of AMLI

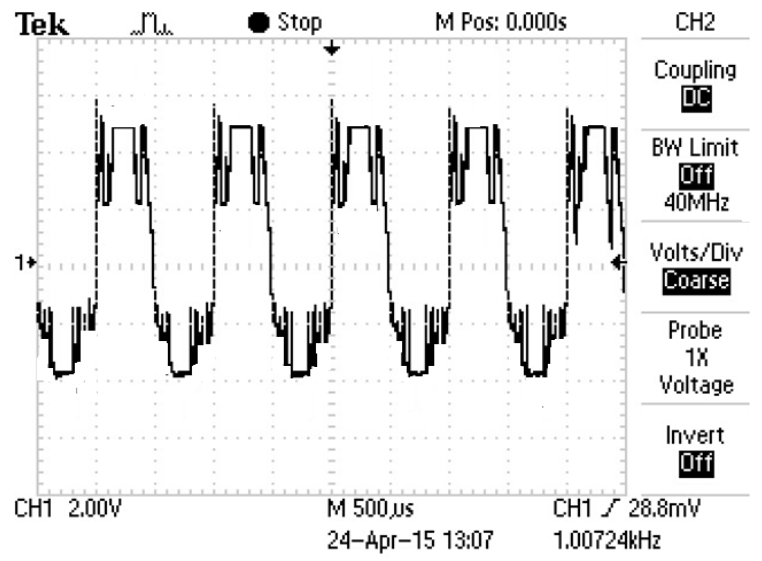

Figure 12: Experimental Results of AMLI 


\section{CONCLUSION}

In this paper, VAPOD hybrid modulation is found to be effective in reducing THD and improving spectral quality of output compared to the conventional methods for producing fifteen level output voltage waveform. And hence AMLI with VAPOD is successfully implemented for fuel cell applications. The simulation and experimental results for fifteen level AMLI have been presented and verified. Therefore, the proposed asymmetric MLI with reduced number of switches is an appropriate topology for fuel cell applications.

\section{ACKNOWLEDGEMENT}

The authors wish to thank the SSN Management for providing the financial support in carrying out this research work.

\section{REFERENCES}

[1] Dharani S and R. Seyezhai : 'Development of Asymmetric Multilevel Inverter with Reduced Number of Switches for Fuel Cells, Global Journal of Advanced Research, Vol. 1,issue1, 2014.

[2] Rasoul Shalchi Alishah, Daryoosh Nazarpour, Seyyed Hossein Hosseini, Mehran Sabahi,:'New Hybrid Structure for Multilevel inverter with fewer number of components for high voltage level' IET power electronics., 2014, Vol. 7, Issue. 1, pp. 96-104.

[3] E. Babaei, S. Alilu, and S. Laali, "A new general topology for cascaded multilevel inverters with reduced number of components based on developed H-bridge," IEEE Trans. Ind. Electron., vol. 61,no. 8, pp. 3932-3939, Aug. 2014.

[4] E.Sambath, S.P. Natarajan, C.R.Balamurugan: 'Performance Evaluation of Multi Carrier Based PWM Techniques for Single Phase Five Level H-Bridge Type FCMLI' IOSR Journal of Engineering (IOSRJEN), Volume 2, Issue 7(July 2012),pp. 82-90.

[5] Keivani.H, M.R.Askari, F.Kavahnia, Aghdam, A. Mohammadi(2006), 'Novel multicarrier PWM method for a three phase cascaded H-bridge multilevel inverter', in Proc. 41st International Universities Power Engineering Conference,UPEC 2006, Vol .2, pp- 593 - 597.

[6] McGrath B.P, Holmes D.G, 'Multicarrier PWM strategies for Multilevel Inverters', IEEE Transactions on Industrial Electronics, Vol.49, Issue 4, Pages: 858 - 867, 2011.

[7] Radan, A.H.Shahirinia, M.Falahi 'Evaluation of Carrier Based PWM Methods for Multi-level Inverters', in Proc. IEEE International Symposium on Industrial Electronics,ISIE07,pp.389-394, 2007.

[8] Ozpineci.B, L. M. Tolbert, Zhong Du, 'Optimum fuel cell utilization with multilevel inverters', in Proc. IEEE 35th Power Electronics Specialist Conference, PESC'04, Vol.6, pp. 4798 - 4802, 2004.

[9] Gupta, K.K., Jain, S.: 'A multilevel voltage source inverter (VSI) to maximize the number of levels in output waveform', Elsevier J. Electr. Power Energy Sys., 2012, 1, (44), pp. 25-36. 